\title{
CLINICAL PHOTO-ATLAS \\ Subconjunctival Haemorrhage (SCH)
}

\section{A Rubin}

Department of Optometry, University of Johannesburg, PO Box 524, Auckland Park, 2006 South Africa
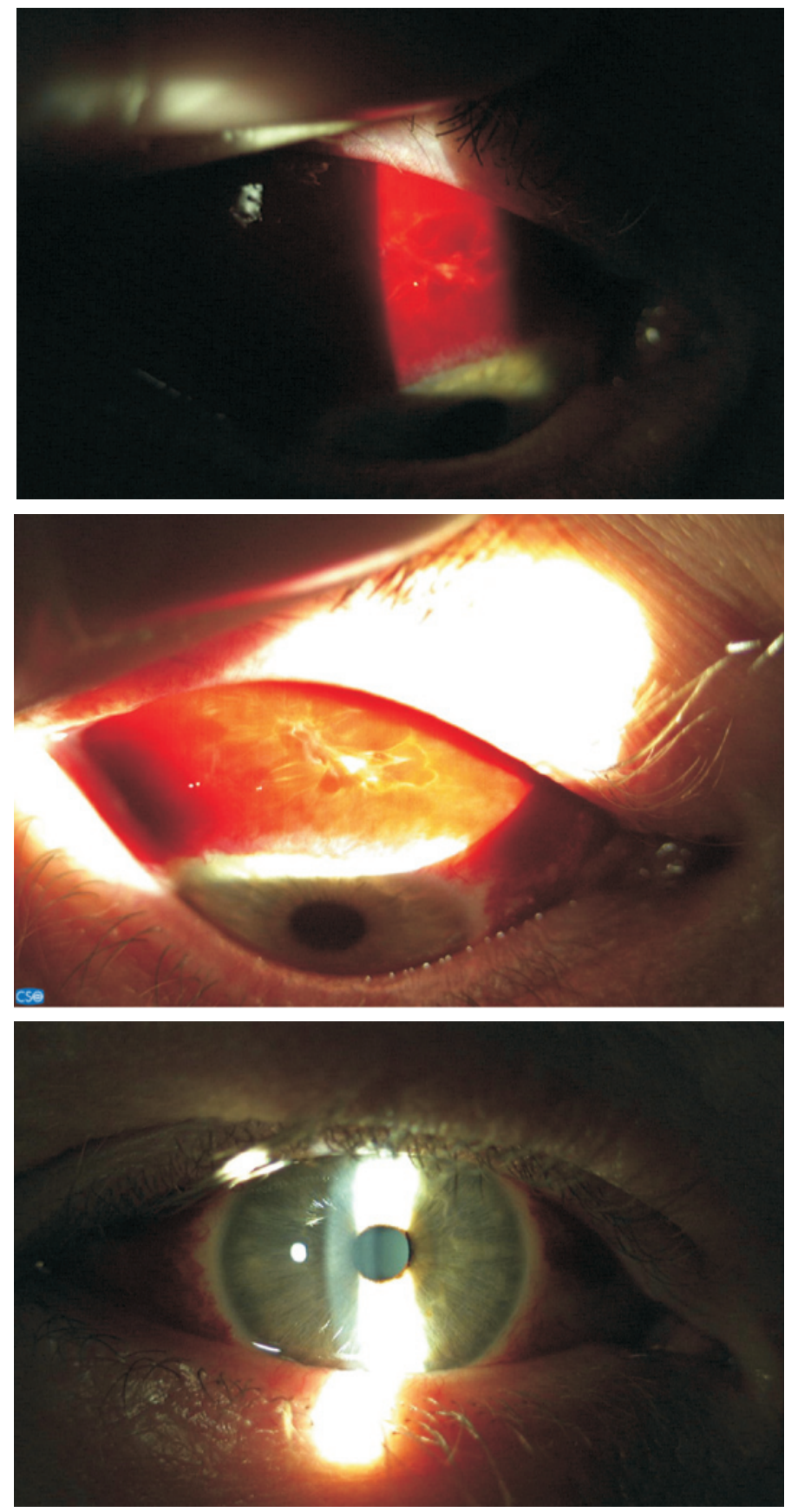

Biomicroscopy and photographs by Professor WDH Gillan, Department of Optometry, University of Johannesburg, South Africa
A 50-year old individual (the author, AR) presented at the University of Johannesburg Optometry clinic with an acute subconjunctival haemorrhage (possibly of traumatic origin) involving the right eye. This patient reported sharp pain following eye rubbing while reading in the evening and thought this might be related to the subsequent $\mathrm{SCH}$ that was first noticed on waking. There was no fever or other relevant symptoms or history other than hyperlipidemia (currently under treatment). General health was good with no history of hypertension, diabetes or other known vascular disease. The cornea was unaffected and no ocular discharge was present. No ocular discomfort or pain was reported after the SCH was noticed immediately after waking. The haemorrhage was extensive and involved most of the superior, nasal and temporal bulbar conjunctiva (see photographs). Blood pressure was somewhat elevated $(145 / 95 \mathrm{~mm} \mathrm{Hg})$ at the time of examination but vision with the habitual compensation was unaffected. Intra-ocular pressure was 20 $\mathrm{mmHg}$ in the right eye.

The differential diagnosis of subconjunctival haemorrhages includes hyperacute (haemorrhagic) or viral or bacterial conjunctivitis (often Strep. pneumoniae or H. aegypticus), Kaposi's sarcoma (which can mimic SCH when located in the conjunctiva) and conjunctival telangiectasia. ${ }^{1}$ Herpes Zoster Ophthalmicus is another possible associated factor with $\mathrm{SCH}$ but here ocular pain and the characteristic vesicular rash on forehead (and tip of the nose as in Hutchinson's sign) would accompany SCH. ${ }^{2}$ Traumatic causes can include blunt injury, corneal burns or episodes of eye rubbing. ${ }^{3}$ Foreign bodies or ill-fitting contact lenses can sometimes lead to $\mathrm{SCH} .{ }^{3}$ Conjunctival lacerations and tissue perforations should be ruled out through biomicroscopy and use of $\mathrm{NaFl}$ and ophthalmoscopy is also necessary to rule out intraocular involvement or haemorrhages. Systemic condi- 
tions that might produce $\mathrm{SCH}$ include hypertension, diabetes, gout, HIV-AIDS, cardiovascular disease or haematological dyscrasias, febrile diseases or malignancies such as leukemia., $13 \mathrm{SCH}$ is also seen as an early ocular sign with thrombocytopenia (low platelet count) purpura. ${ }^{4}$ Bilateral SCH might indicate child or adult abuse $\mathrm{e}^{5}$ or systemic disease as above. Menstruation, or Valsalva-like manoeuvres associated with coughing (especially chronic cough), sneezing, vomiting, constipation, seizure or strangulation may be relevant sometimes. ${ }^{3}$ Respiratory distress can also produce $\mathrm{SCH} .{ }^{6}$ Sometimes $\mathrm{SCH}$ relates to nutritional agents such as oral L-arginine-based supplements ${ }^{7}$ used by body builders, for example. Apparently the supplement produces vasodilation and an antithrombotic effect due to nitric oxide from arginine. Extensive exercise can also sometimes be associated with $\mathrm{SCH}$. Aspirin, and anticoagulant and antithrombotic drugs such as Warfarin can also produce $\mathrm{SCH} .{ }^{8} \mathrm{Oph}-$ thalmic surgery such as LASIK or for strabismus or cataract extraction also can have the complication of $\mathrm{SCH}$. Other medical procedures such as endoscopy used in gastroenterology, for example, can also sometimes lead to $\mathrm{SCH}$ due to gagging or vomiting that occasionally occurs with the procedure..$^{9}$ Intracranial, retinal and $\mathrm{SCH}$ with sometimes neurological impairment can occasionally occur in premature neonates. ${ }^{10}$ Conjunctival amyloidois (a relatively rare condition where a vascularised, and possibly haemorrhagic, conjunctival yellowish or yellow-pink mass (diffuse or circumscribed) is found usually in an elderly patient) and $\mathrm{SCH}$ can be associated. ${ }^{11}$ Occasionally SCH can be idiopathic. ${ }^{1,4}$

Treatment involves medical referral where appropriate and careful monitoring of the patient at regular intervals for possible recurrence. In the early stages, possibly alternating hot and cold compresses and vasoconstrictors may assist slightly towards resolution. Usually the problem of SCH will resolve without complication within 7-21 days and the SCH may become pink, orange, yellow or black (if the blood remains long enough) before clearing but permanent blood staining rarely occurs. ${ }^{3}$ In patients where $\mathrm{SCH}$ is recurrent or is otherwise suspicious referral for thorough medical assessment and possible treatment is important. $\mathrm{SCH}$ can occasionally be suggestive of serious or even life-threatening conditions like leukemia or other complications relating to drug usage (for instance, with warfarin) where urgent medical attention is essential.

\section{References}

1. Kanski JJ. Clinical ophthalmology: a systematic approach, 5th Ed. Edinburgh: Butterworth-Heinemann, 2003.

2. Binder NR, Holland GN, Hosea S, Silverberg ML. Herpes Zoster Ophthalmicus in an otherwise-healthy child. J AAPOS $20059597-598$.

3. Catania LJ. Primary care of the anterior segment. California: Appleton \& Lange, 1988.

4. Sodhi PK, Jose R. Subconjunctival hemorrhage: the first presenting clinical feature of idiopathic Thrombocytopenic Purpura. Japanese J Ophthalmol 200347 316-318.

5. Spitzer SG, Luorno J, Noël L. Isolated subconjunctival hemorrhages in nonaccidental trauma. J AAPOS 2005953 56.

6. Chiu C, Chuang Y, Su L. Subconjunctival haemorrhage and respiratory distress. Lancet 2001358724.

7. Randhawa S, Abowd M, Sharma A, Weiss JS. Anterior segment complications of a nutritional supplement. J Cataract Refract Surg 33 2007, 918-920.

8. Bodack MI. A warfarin-induced subconjunctival hemorrhage. Optometry $2007 \mathbf{7 8} 113-118$.

9. Rajvanshi P, McDonald GB. Subconjunctival hemorrhage as a complication of endoscopy. Gastrointest Endosc 2001 53 251- 253.

10. Anteby II, Anteby EY, Chen B, Hamvas A, McAlister W, Tychsen L. Retinal and intraventricular cerebral hemorrhages in the preterm infant born at or before 30 weeks' gestation. J AAPOS 20015 90-94.

11. Demirci H, Shields CL, Eagle RC, Shileds JA. Conjunctival amyloidosis: Report of six cases and review of the literature. Surv Ophthalmol 200651 419-433. 